\title{
Patient and public involvement in sexual and reproductive health: a new editor, and a new tool
}

\section{Linda Pepper}

\section{Correspondence to}

Linda Pepper, Patient and Public Involvement (PPI) Editor, BMJ Sexual \& Reproductive Health, London, UK; l.pepper@virgin.net

Received 19 September 2018 Accepted 19 September 2018

\section{Sinked}

- http://dx.doi.org/10.1136/ bmjsrh-2018-200082

Check for updates

(C) Author(s) (or their employer(s)) 2018. No commercial re-use. See rights and permissions. Published by BMJ.

To cite: Pepper L. BMJ Sex Reprod Health

2018;44:237-238.
Most healthcare organisations now realise the importance of a patient or consumer focus to improve healthcare outcomes and patient satisfaction. In common with some other BMJ journals, BMJ SRH has taken some first steps towards addressing this deficiency, by introducing a requirement for authors of original research papers to state whether and how they have involved patients or service users in the conception, design and interpretation of their research, ${ }^{1}$ and by appointing me as their Patient and Public Involvement (PPI) Editor.

So who am I? Since becoming sexually active in my late teens, and believing as a woman that in order to control my life I needed to be able to control my fertility, I have had an interest in sexual health, and women's reproductive needs. I have a longstanding involvement in the UK National Health Service (NHS) in Patient and Public Involvement, and have been a member of the Royal College of Obstetricians and Gynaecologists' Women's Health Network. I have been active in sexual and reproductive healthcare $(\mathrm{SRH})$ in particular as a patient, campaigner, member of local and national reproductive rights groups, and a developer of training materials. I have also brought a patient perspective to local NHS bodies and to national organisations. ${ }^{23}$

So what is a patient perspective and how can it be incorporated? Just as the language used around sexual health has been shown to be varied, with professional language not always reflecting that used by the public, ${ }^{4}$ the term 'patient and public involvement' is also interpreted in different ways. The Faculty of Sexual \& Reproductive Healthcare's standard statement on User and Public Involvement states that services should demonstrate that user and public involvement is fundamental to service development, provision, monitoring and evaluation. ${ }^{5}$
INVOLVE - an organisation established in 1996 as part of the UK National Institute for Health Research to support active public involvement in the NHS defines public involvement as "research being carried out 'with' or 'by' members of the public rather than 'to', 'about' or 'for' them". By 'public', INVOLVE means patients and their relatives as well as members of the general public. ${ }^{6}$

The value of patient involvement in research is well documented ${ }^{7-9}$ and it may lead to improved clinical outcomes for patients. However, there are significant challenges. Some have argued ${ }^{10} 11$ that for the sensitive area of SRH in particular, fear of stigma may pose particular challenges in achieving patient involvement. And across the board, work in the area of patient involvement is often still lacking, outputs are variable and such initiatives are not often audited.

An article in this issue of $B M J S R H$ entitled 'Evidence-based patient/public voice: a patient and public involvement audit in the field of sexual health' ${ }^{12}$ seeks to address some of these challenges, offering a tool for measuring the value of PPI in $\mathrm{SRH}$, as a vehicle for improving PPI practice in the sexual health field in terms of defined goals and clearly measurable, auditable outcomes.

The audit tool, consisting of 12 questions drafted by patients covering three clear areas, was piloted in a sexual health setting, then refined and introduced to sexual health research projects. Independent researchers examined the results, identifying themes, and areas for improvement. Results showed wide and varied definition of patient and public involvement and demonstrated the need for greater clarity. It also identified an overreliance on group work and a need for a greater diversity of methods for accessing patient views, and a tendency to conflate qualitative research (ie, expert-designed 
research seeking the views of patients as research participants), with patient involvement in research (ie, the structural involvement of patients in the design and interpretation of studies), and in the discussion about what kind of knowledge should be collected.

This study focused particularly on sexually transmitted infections (STIs). Sexual health is of course much wider than this - the WHO suggests that sexual health is "a state of physical, emotional, mental and social well-being in relation to sexuality; it is not merely the absence of disease ...". ${ }^{13}$ It would be useful to develop audit tools in wider SRH to demonstrate the value of PPI, as not all SRH evokes sensitivity, embarrassment or shame.

Nevertheless, this article is a timely stimulus to both service providers and researchers, and we hope it will generate discussion.

BMJ SRH will be looking to learn from The BMJ's Patient Partnership Strategy. We will be commissioning patient commentaries on published papers where possible, exploring where and how we can involve patients in peer review. We will also be asking authors to tell us how patient priorities, experience, and preferences helped shape research questions and outcome measures, how patients were involved in recruitment and conduct of the study, and how results will be disseminated to the participants who have offered their time.

Patient involvement is an important piece of cultural change in healthcare, and will require commitment, time and sensitivity, and a willingness to experiment and learn from mistakes. BMJ SRH is committed to participating in and encouraging that process, and hope that journal readers will share with us accounts of their own successes and struggles in this area.

Acknowledgements The author would like to thank Toni Belfield (BMJ SRH Sexual Health Information Advisor) for her helpful comments on an earlier draft of this article.

Funding The author has not declared a specific grant for this research from any funding agency in the public, commercial or not-for-profit sectors.

Competing interests None declared.

Patient consent Not required.
Provenance and peer review Commissioned; internally peer reviewed.

\section{REFERENCES}

1 Goldbeck-Wood S, Belfield T. Partnering with patients: how did you involve patients in your research? J Fam Plann Reprod Health Care 2017;43:94-5.

2 BMJ Sexual \& Reproductive Health Blog. https://blogs.bmj. com/bmjsrh/2018/06/28/an-interview-with-linda-pepper/ (accessed 25 Aug 2018).

3 BMJ Sexual \& Reproductive Health Podcast. https:// soundcloud.com/bmjpodcasts/in-conversation-with-the-patientand-public-involvement-editor-linda-pepper? in=bmjpodcasts/ sets/jfprhc-podcast (accessed 25 Aug 2018).

4 Belfield T. Words matter!. J Fam Plann Reprod Health Care 2010;36:55-8.

5 Faculty of Sexual \& Reproductive Healthcare. SRH service standards for sexual and reproductive healthcare. 2016. https:// www.fsrh.org/standards-and-guidance/documents/fsrh-servicestandards-for-sexual-and-reproductive-healthcare/ (accessed 25 Aug 2018).

6 National Institute of Health Service Research (NIHR). INVOLVE. 2017. http://www.invo.org.uk/about-involve (accessed 25 August 2018).

7 Public Involvement Standards Development Partnership. National standards for public involvement in research. 2018. http://nihr.ac.uk/news-and-events/documents/public (accessed 25 Aug 2018).

8 Wicks P, Richards T, Denegri S, et al. Patients' roles and rights in research. BMJ 2018;362:k3193.

9 All-Party Parliamentary Group on Sexual and Reproductive Health in the UK. Breaking down the barriers: the need for accountability and integration in sexual health, reproductive health and HIV services in England. 2015. https:/www.fpa. org.uk/sites/default/files/breaking-down-the-barriers-reportappg-srhuk.pdf (accessed 26 Aug 2018).

10 Meyrick J, Gray D, Jones A. Assessing the possibilities and challenges of patient involvement in sexual, reproductive and HIV/AIDS services. Sex Health 2016;13:213-20.

11 Lorenc A, Robinson N. A tool to improve patient and public engagement in commissioning sexual and reproductive health and HIV services. J Fam Plann Reprod Health Care 2015;41:8-12.

12 Meyrick J, Gray D. Evidence-based patient/public voice: a patient and public involvement audit in the field of sexual health. BMJ Sex Reprod Health 2018;44:267-71.

13 World Health Organization (WHO). Sexual and Reproductive Health: defining sexual health 2006. http://www.who.int/ reproductivehealth/topics/sexual (accessed 25 Aug 2018). 